\title{
Application of Chemometrics Into Removal of Dyes by NaX Nanozeolites: Simultaneous Model
}

Siroos Shojaei ( $\square$ shojaeisiroos@gmail.com )

University of Sistan and Baluchestan

\section{Saeed Shojaei}

University of Tehran

Shahab S. Band

National Yunlin University of Science and Technology

\section{Research Article}

Keywords: Auramine-O, Chemometrics, Malachite green, NaX nanozeolites, Ultrasound-assisted adsorption

Posted Date: April 12th, 2021

DOl: https://doi.org/10.21203/rs.3.rs-382635/v1

License: (c) (i) This work is licensed under a Creative Commons Attribution 4.0 International License.

Read Full License

Version of Record: A version of this preprint was published at Scientific Reports on August 6th, 2021. See the published version at https://doi.org/10.1038/s41598-021-95649-5. 


\title{
Application of chemometrics into removal of dyes by NaX nanozeolites: Simultaneous model
}

\author{
Siroos Shojaei ${ }^{1, *}$, Saeed Shojaei ${ }^{2}$, Shahab S.Band ${ }^{3}$
}

${ }^{1}$ Department of Chemistry, Faculty of Sciences, University of Sistan and Baluchestan, Zahedan 98135-674, Iran shojaeisiroos@gmail.com

${ }^{2}$ Department of Arid and Mountainous Regions Reclamation, Faculty of Natural Resources, University of Tehran, Tehran, Iran.

${ }^{3}$ Future Technology Research Center, National Yunlin University of Science and Technology, 123 University Road, Section 3, Douliou, Yunlin 64002, Taiwan.

\begin{abstract}
In the present study, the simultaneous removal of malachite green $(\mathrm{MG})$ and auramine-O (AO) dyes from the aqueous solution by $\mathrm{NaX}$ nanozeolites in a batch system is investigated. Taguchi method and response surface methodology (RSM) were used to optimize and model dye removal conditions. In order to do so, the effect of various factors (dyes concentration, sonication time, ionic strength, adsorbent dosage, temperature, and $\mathrm{pH}$ of the solution) on the amount of dye removal was evaluated by the Taguchi method. Then, the most important factors were chosen and modeled by the RSM method so as to reach the highest percentage of dye removal. The proposed quadratic models to remove both dyes were in good accordance with the actual experimental data. The maximum removal efficiencies of MG and AO dyes in optimal operating conditions were \%99.07 and \%99.61, respectively. Also, coefficients of determination $\left(\mathrm{R}^{2}\right)$ for test data were 0.9983 and 0.9988 for MG and AO dyes, respectively. The reusability of NaX nanozeolites was evaluated during the adsorption process of MG and AO. The results showed that the adsorption efficiency decreases very little up to 5 cycles. Moreover, NaX nanozeolites were also applied as adsorbents to remove MG and AO from environmental water samples and more than $\% 98.1$ of both dyes were removed from the solution in optimal conditions.
\end{abstract}

Keywords: Auramine-O, Chemometrics, Malachite green, NaX nanozeolites, Ultrasound-assisted adsorption

\section{Introduction}

Pollution of water resources has become one of the economic problems since industrial factories have been increasing and water resources are limited [1,2]. Numerous industries such as textiles, pharmaceuticals, and papermaking, produce large volumes of dye effluents. It is reported that about 10,000 types of commercial dyes with a volume of 
more than 700,000 tons are produced worldwide. In fact, about $20 \%$ of these dyes enter the aqueous medium due to the lack of proper stabilization of dye molecules on the fibers and the inefficiency of dyeing factories in wastewater treatment. Studies have shown that most of these dyes are toxic, allergenic, carcinogenic, and mutagenic to humans and various organisms [3,4].

Malachite green (MG) is a toxic cationic dye that was originally used in the dyeing industry for materials such as silk, leather, and paper. This dye was first used in the fisheries industry in 1933 [5]. Because of being too inexpensive and its effectiveness in eradicating aquatic infections, this dye was used too much in many countries. On the other hand, as a result of using this dye, many destructive effects such as carcinogenicity and mutagenicity have been reported in various organisms, especially mammals [6,7].

Auramine-O (AO) is a water-soluble cationic dye. AO dye is one of the dyes used in the textile, carpet, and leather industries. Studies have shown that this dye is converted to biotransformation in human organs and increases the risk of bladder cancer [8,9]. Accordingly, efforts should be made to improve methods that reduce or eliminate these dyes from the aqueous environment.

There are different ways to remove the dye such as reverse osmosis, ultra-filtration, ion exchange, and adsorption [1016]. Adsorption is one of the acceptable techniques to reduce the concentration of dissolved dyes in aqueous solutions. The advantages of this technique include simplicity in operation, cheapness, and flexibility compared to other separation techniques $[17,18]$.

Various adsorbents such as eggshell [19], activated carbon [20], bentonite [21], shrimp shell [22] and zeolite [23] have been used to remove dye effluents. Recently, researchers have applied inexpensive adsorbents with high adsorption potential that have high adsorption power, high adsorption power, and also do not harm the environment. Thus, economic problems and the recovery of adsorbents have made researchers focus on inexpensive adsorbents such as zeolites.

Zeolites are generally divided into natural and synthetic. Natural zeolites are mostly found in volcanic rocks, but they are not produced a lot because it is not economical to extract them. Synthetic zeolites are far better than their natural counterparts due to being composed of a special type, high purity, easy commercial-scale access, and having fixed and controllable pore sizes. The most popular synthetic zeolites include A, X, Y and ZSM-5 [24, 25]. In synthetic 
zeolites, there are fundamental changes in the properties of these materials as the particle size is reduced from micrometers to nanometers, which is very effective on the function of zeolites in catalytic applications and separation. As the particle size decreases, the ratio of the number of outer atoms to the material increases rapidly, resulting in an increase in the outer surface area and significant surface activity [26, 27]. Nowadays, the use of zeolites as adsorbents in the adsorption process has received much attention. A research was conducted on the application of ZSM-5 zeolite to remove malachite green from aqueous solutions. optimum condition zeolite dosage $5 \mathrm{wt} \%, \mathrm{pH}=10$, initial dye concentration of $10 \mathrm{mg} \mathrm{L}^{-1}$, and temperature $25^{\circ} \mathrm{C}$ was obtained. Also, $99.12 \%$ dye removal was achieved in optimal conditions [28]. In another study, nano ZSM-5 zeolite (nZSM-5) synthesized from rice husk ash to remove crystal violet from aqueous solutions was carried out by Sivalingam and Sen (2020), and the effectiveness of nZSM-5 in removing crystal violet from aqueous solutions was investigated. Maximum dye removal (99.99\%) in conditions adsorbent dosage of $100 \mathrm{mg}, \mathrm{pH}$ of 8 , initial CV dye concentration of $100 \mathrm{mg} \mathrm{L}^{-1}$, and sonication time of 30 min was obtained [29]. Sivalingam and Sen used nanozeolite $\mathrm{X}$ to remove ions such as $\mathrm{Cu}^{2+}, \mathrm{Zn}^{2+}, \mathrm{Pb}^{2+}, \mathrm{Cd}^{2+}, \mathrm{Ca}^{2+}, \mathrm{Ni}^{2+}, \mathrm{Mg}^{2+}$, and various dyes such as crystal violet, methylene blue, Congo red, and indigo carmine. The results showed that the maximum adsorption capacity of metals was obtained for $\mathrm{Pb}^{2+} 196.24 \mathrm{mg} \mathrm{g}^{-1}$ and methylene blue $193.45 \mathrm{mg} \mathrm{g}^{-1}$. Therefore, nanozeolite $\mathrm{X}$ can be used as a highly efficient adsorbent to remove a variety of dyes and ions [30].

The ultrasonic process has been considered as an efficient and advanced technology in various fields of science to help eliminate contaminants in water [31]. Theory to explain how ultrasound breaks chemical bonds involves the formation, growth, and eventual destruction of a bubble that forms within a liquid. This phenomenon, known as acoustic cavitation, creates an environment with a pressure of up to 10 pascals. The phenomenon of acoustic cavitation increases mass transfer, increases the adsorption permeability into the adsorbent, and increases process efficiency, and reduces time $[32,33]$.

Generally, experiments and factors affecting the process are carried out in the form of one-factor-at-a-time. The effect of different factors in this method is done by changing the effective factor studied, in a range of levels and keeping other factors constant. To achieve optimal conditions by this method, the tests must be repeated for all factors, which leads to a very large increase in the number of tests. In order to cope with the limitations, various experimental design methods based on mathematical and statistical techniques have been developed, including the Taguchi method and response surface methodology (RSM) [34, 35]. Taguchi method includes experimental design method to determine 
the effect of factors on the response and to obtain the optimal process conditions. One of the main advantages of this method is providing optimal conditions with the minimum number of experiments using orthogonal arrays, which ultimately leads to cost reduction [36, 37]. RSM is very useful to design experiments and analyze data so that it can lead to a purposeful and reliable conclusion. RSM is a special set of mathematical and statistical methods used to design experiments, construct models, evaluate optimal conditions, effect independent variables on dependent variables, and obtain optimal conditions for multiple responses simultaneously. Also, the graphs presented in the RSM method are three-dimensional, which allows showing the change of all factors in one graph $[38,39]$. The aim of this study was to remove toxic dyes by $\mathrm{NaX}$ nanozeolites as well as the variables were first examined based on Taguchi method and the most important ones were selected. In the next step, these variables were modeled using RSM method to determine the optimal conditions.

\section{Experimental section}

\subsection{Materials and instruments}

All materials used such as sodium aluminate, sodium hydroxide, tetraethylorthosilicate, hydrochloric acid, and other chemicals were used without further refining and were supplied from Aldrich or Merck companies. The stock solution of the dyes was prepared by dissolving the solid substance of each dye in distilled water. Other solutions in this study were prepared by diluting the stock solution and used immediately in adsorption experiments. UV/Vis spectrophotometer (2120 UV plus, Optizen) was used to detect dyes at maximum wavelength of malachite green (MG) $\left(\lambda_{\max }=620 \mathrm{~nm}\right)$ and auramine- $\mathrm{O}(\mathrm{AO})\left(\lambda_{\max }=430 \mathrm{~nm}\right)$. Sodium hydroxide $(1 \mathrm{M})$ and hydrochloric acid $(1 \mathrm{M})$ solutions were used to adjust the $\mathrm{pH}$. The chemical structures and descriptions of the dyes are shown in Figure 1 and Table 1, respectively.

Table 1. The characteristics of the dyes.

\begin{tabular}{llll}
\hline Dye & Dye formula & $\lambda_{\max }(\mathrm{nm})$ & Molecular weight $\left(\mathrm{g} \mathrm{mol}^{-1}\right)$ \\
\hline Malachite green & $\mathrm{C}_{23} \mathrm{H}_{25} \mathrm{~N}_{2}$ & 620 & 364.911 \\
Auramine-O & $\mathrm{C}_{17} \mathrm{H}_{22} \mathrm{ClN}_{3}$ & 430 & 303.83 \\
\hline
\end{tabular}


(a)

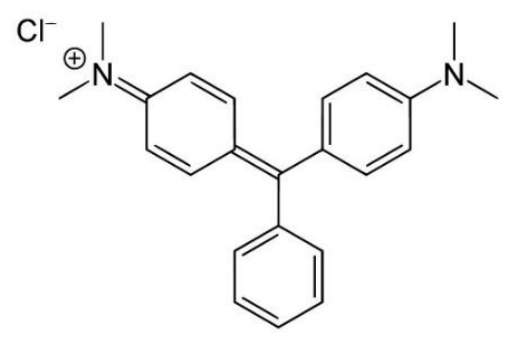

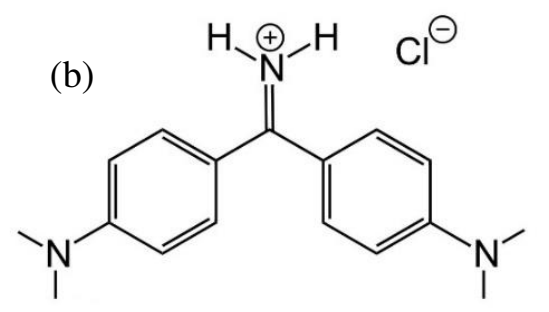

Fig. 1. The chemical structure of (a) MG, and (b) AO.

\subsection{Preparation of NaX nanozeolites}

In order to synthesize $\mathrm{NaX}$ nanozeolites, molecular composition (5.5 $\mathrm{Na}_{2} \mathrm{O}: 1.0 \mathrm{Al}_{2} \mathrm{O}_{3}: 4.0 \mathrm{SiO}_{2}: 190 \mathrm{H}_{2} \mathrm{O}$ ) was used. Also, $7.22 \mathrm{~g}$ of sodium hydroxide was calculated according to the molar composition and dissolved in a plastic bottle $(250 \mathrm{ml})$ with distilled water. Then, the solution was divided into two equal parts and in the first part, $0.16 \mathrm{~g}$ of sodium aluminate and the second part $5.22 \mathrm{~g}$ of Tetraethyl orthosilicate were added. The two solutions including aluminate and silicate solutions were then mixed and placed in an ice-water bath. Hydrothermal crystallization was done by shaking with a shaker for 3 days. Furthermore, the obtained powder was recovered by centrifugation. The synthesized $\mathrm{NaX}$ nanozeolites were washed several times with distilled water to bring the $\mathrm{pH}$ below 8 and finally dried at room temperature for 1 day $[40,41]$. The structure of the samples was studied using X-ray diffraction (XRD) using Cu $\mathrm{K}_{\mathrm{a}}$ as the radiation source. The morphology of $\mathrm{NaX}$ nanozeolites was also examined through scanning electron microscopy (SEM).

\subsection{Experimental design}

\subsubsection{Taguchi method}

Taguchi is a method that reduces the number of experiments by minimizing the interference of uncontrolled factors, which is used as a mathematical technique. Creating orthogonal arrays and matching a large number of factors, Taguchi identifies minor variables in the shortest amount of time. The orthogonal arrays are shown in Table 2. Factors studied include temperature $\left(25-35{ }^{\circ} \mathrm{C}\right)$, solution $\mathrm{pH}(3-9)$, adsorbent $(100-300 \mathrm{mg})$, ionic strength $(0-6 \mathrm{w} / \mathrm{v} \%)$, dye 
concentration (6-10 $\left.\mathrm{mg} \mathrm{L}^{-1}\right)$ and sonication time (3-9 min). Applying the Taguchi method, only 27 experiments are required to obtain the optimal levels of the variables (Table 2), while the most accurate optimization method for a complete study of seven variables at three levels requires 2187 experiments $\left(3^{7}=2187\right)$, which is practically timeconsuming. Therefore, the Taguchi method can reduce the number of tests, reduce time, decrease costs, and determine important factors in a short time. Taguchi uses the signal-to-noise ratio in measurable amounts of qualitative characteristics according to the purpose of the experiments. The signal-to-noise ratio (S/N) is obtained by Equation 1:

$\frac{S}{N}=-10 \log \left(\frac{1}{n} \sum_{k=1}^{n} \frac{1}{y_{i}^{2}}\right)$

In this equation, $\mathrm{n}$ is the number of experiments and $\mathrm{y}$ is the response of the variables [42].

Table 2. Process variables with their values.

\begin{tabular}{lllll}
\hline Variables & Unit & Level 1 & Level 2 & Level 3 \\
\hline Adsorbent dosage & $\mathrm{mg}$ & 100 & 200 & 300 \\
MG concentration & $\mathrm{mg} \mathrm{L}^{-1}$ & 6 & 8 & 10 \\
AO concentration & $\mathrm{mg} \mathrm{L}^{-1}$ & 6 & 8 & 10 \\
Ionic strength & $(\mathrm{w} / \mathrm{v} \%)$ & 0 & 3 & 6 \\
pH of the solution & --- & 4 & 6 & 8 \\
Temperature & ${ }^{\circ} \mathrm{C}$ & 25 & 27 & 30 \\
Sonication time & $\min$ & 3 & 6 & 9 \\
\hline
\end{tabular}

\subsubsection{Response surface methodology (RSM)}

RSM is a set of mathematical and statistical methods that determines the relationship between one or more responses to several variables. In chemistry, many phenomena are modeled based on their own theories. However, many phenomena do not have may not have a satisfactory mathematical model due to their dependence on a large number of controlling factors, unknown mechanisms, and mathematical complexity. In such cases, the use of experimental modeling methods such as the response level method is effective. In the central composite design (CCD)-based response level method, variables are examined at five levels. Low levels $(-\alpha)$ and high levels $(+\alpha)$ are entered into the software by the operator and other levels are provided by the software. According to the results obtained in the Taguchi method in section 2.3.1. Taguchi method, in this step, five factors that were of great importance were examined. These factors were the amount of adsorbent, dye concentration, sonication time, and $\mathrm{pH}$ of the solution (Table 3). The 
percentage of dye removal was considered as the response variable. The equation that can be used in the response surface method is the polynomial quadratic equation. The responses must conform to Equation 2 in order to use it.

$\mathrm{Y}=\beta_{0}+\sum_{i=1}^{k} \beta_{i} X_{i}+\sum_{i=1}^{k} \beta_{i i} X_{i}^{2}+\sum_{i \leq j}^{k} \sum_{j}^{k} \beta i j X_{i} X_{j}+e$

Where $\mathrm{k}$ is the number of variables, $\beta_{0}$ is the model constant, $\beta_{i}$ are the coefficients of linear factors, $\beta_{i j}$ and $\beta_{i i}$ are the coefficients of the factors that interact with each other, $\varepsilon$ the remaining values are related to random error, $X_{i}$ and $X_{j}$ are the variables [43].

Table 3. Levels of the variable in the RSM.

\begin{tabular}{lccccccc}
\hline \multicolumn{1}{c}{ Variables } & Symbol & Unit & \multicolumn{5}{c}{ Levels } \\
\cline { 4 - 8 } & & & $-\alpha$ & Lower & Central & Upper & $+\alpha$ \\
\hline Adsorbent dosage & $\mathrm{A}$ & $\mathrm{mg}$ & 200 & 250 & 300 & 350 & 400 \\
pH of the solution & $\mathrm{B}$ & --- & 4 & 6 & 8 & 10 & 12 \\
MG concentration & $\mathrm{C}$ & $\mathrm{mg} \mathrm{L}^{-1}$ & 2 & 4 & 6 & 8 & 10 \\
AO concentration & $\mathrm{D}$ & $\mathrm{mg} \mathrm{L}^{-1}$ & 2 & 4 & 6 & 8 & 10 \\
Sonication time & $\mathrm{E}$ & $\mathrm{min}$ & 3 & 6 & 9 & 12 & 15 \\
\hline
\end{tabular}

\subsection{Analytical methods}

In order to study the efficiency of $\mathrm{NaX}$ nanozeolites to remove $\mathrm{MG}$ and $\mathrm{AO}$ dyes, batch experiments were performed. The experiments were designed by the CCD method. For this reason, at room temperature, in a centrifuge tube, 25 $\mathrm{mL}$ of a solution containing both dyes $\left(4 \mathrm{mg} \mathrm{L}^{-1}\right)$ was added. Then, $347 \mathrm{mg}$ of NaX nanozeolites were added to the sample solution. The $\mathrm{pH}$ of the solution was adjusted to 8 . Following that, the solution was placed in an ultrasonic bath for 11.5 minutes and also centrifuged at $3000 \mathrm{rpm}$ for 5 minutes. Finally, the supernatant was removed and transferred to UV/Vis cells to determine the amount of residual concentration and to calculate the percentage of dye removal of MG and AO, and the adsorption of solutions for MG and AO was read at $620 \mathrm{~nm}$ and $430 \mathrm{~nm}$, respectively. In these experiments, Equation 3 was used to determine the percentage of dye removal.

$\%$ Removal $=\left(\frac{C_{0}-C}{C_{0}}\right) \times 100$

where $\mathrm{C}_{0}$ and $\mathrm{C}$ are the initial and final concentrations of the desired dye in terms of $\mathrm{mg} \mathrm{L}^{-1}$, respectively [44]. 


\section{Results and discussion}

\subsection{Characterization of the NaX nanozeolites}

Figure 2 shows the XRD pattern of the sample and XRD analysis shows that high purity NaX zeolite phase without phase interference has been synthesized in the above phase method. The average size of the crystals synthesized using the Scherer equation was in the range of 40-70 nm. The crystal size indicates that the synthesis of NaX zeolite in nanometer dimensions has been successful. Morphological analysis of NaX nanozeolites was performed using SEM. The SEM image of the synthesized zeolite sample (Inset of Fig. 2) shows that the particle sizes are in the range between $60-200 \mathrm{~nm}$.

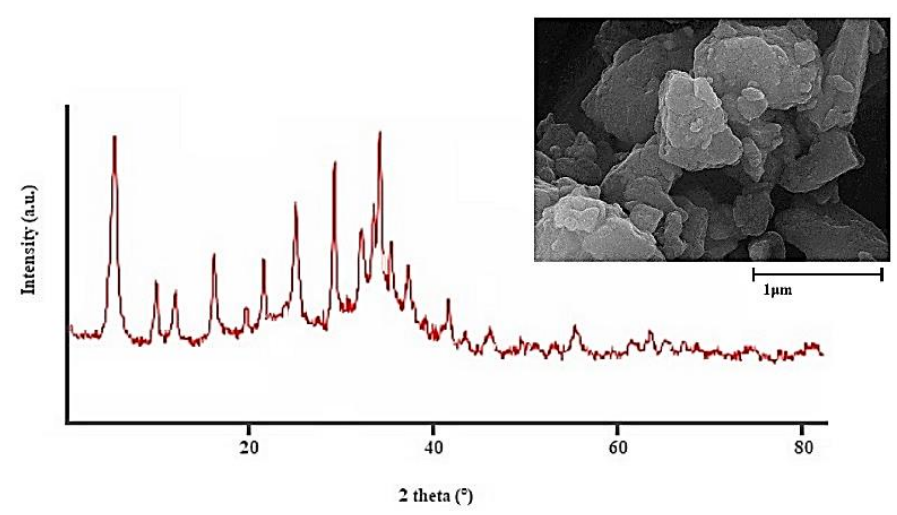

Fig. 2. XRD pattern of nanozeolite-X. Inset shows SEM image of corresponding sample.

\subsection{Determination of $\mathrm{PH}_{P Z C}$}

$\mathrm{pH}_{\mathrm{PZC}}$ is the point at which the adsorbent surface charge is neutral. Thus, at a $\mathrm{pH}$ above this point, the adsorbent surface has a negative charge and at a lower $\mathrm{pH}$, the surface charges become positive. In order to determine $\mathrm{pH}$ PZC, 10 $\mathrm{mL}$ of $\mathrm{NaCl}$ solution $(0.1 \mathrm{M})$ was poured into separate test tubes and the solutions were adjusted to different $\mathrm{pH}$ (212). Hydrochloric acid ( $1 \mathrm{M})$ and sodium hydroxide $(1 \mathrm{M})$ were used to adjust the $\mathrm{pH}$. Then, $0.3 \mathrm{~g}$ of adsorbent was added to the solutions and the samples were placed in a shaker at $150 \mathrm{rpm}$. After 24 hours, the adsorbents were separated from the solution and the $\mathrm{pH}$ of the solutions was measured again. The $\mathrm{pH}$ PZC was found to be 6.5 (Fig. S1). 


\subsection{Response factors based on the Taguchi}

The experimental design was performed by the Taguchi method in Minitab software version 19. In order to estimate the most important factors in the removal of MG and AO dyes by NaX nanozeolites by the Taguchi method, 7 factors were investigated at 3 levels. These levels were initially obtained by trial and error. The orthogonal table $\mathrm{L}_{27}$ ( 7 factors in 3 levels) was proposed by the software to design the above experiment, which includes 27 experiments. Taguchi test design table for removing MG and AO dyes is given in Table S1.

The change in each of the factors indicates the importance of the factor in the process. In Table 4, the effect of each factor at each level was calculated independently by the software and finally, according to the differences created in each factor, the importance of the effect of each was investigated. In MG and AO dye removal experiments, the amount of adsorbent has the first effect on the adsorption process, $\mathrm{pH}$ comes as the second factor, MG dye concentration the third, $\mathrm{AO}$ dye concentration the fourth, sonication time the, ionic strength the sixth, and finally the temperature is the seventh factor. Based on the results of Table 4, the variables of adsorbent amount, solution $\mathrm{pH}$, dye concentration, and sonication time were selected as effective variables for optimization and modeling by the RSM method. Therefore, the variables of temperature and ionic strength were omitted. Because as shown in Figure 3 and Table 4, the temperature has little effect on the process compared to other factors and was maintained at $25{ }^{\circ} \mathrm{C}$ in subsequent optimal experiments. Increasing ionic strength also reduces the adsorption of dyes by NaX nanozeolites. The reason for this can be attributed to preventing dye molecules from approaching the active sites of adsorption [45]. In the literature, the same effect has been reported for some cationic dyes, such as the adsorption of methylene blue by sludge ash, methylene blue, and crystal violet by palm kernel fiber [46, 47]. 


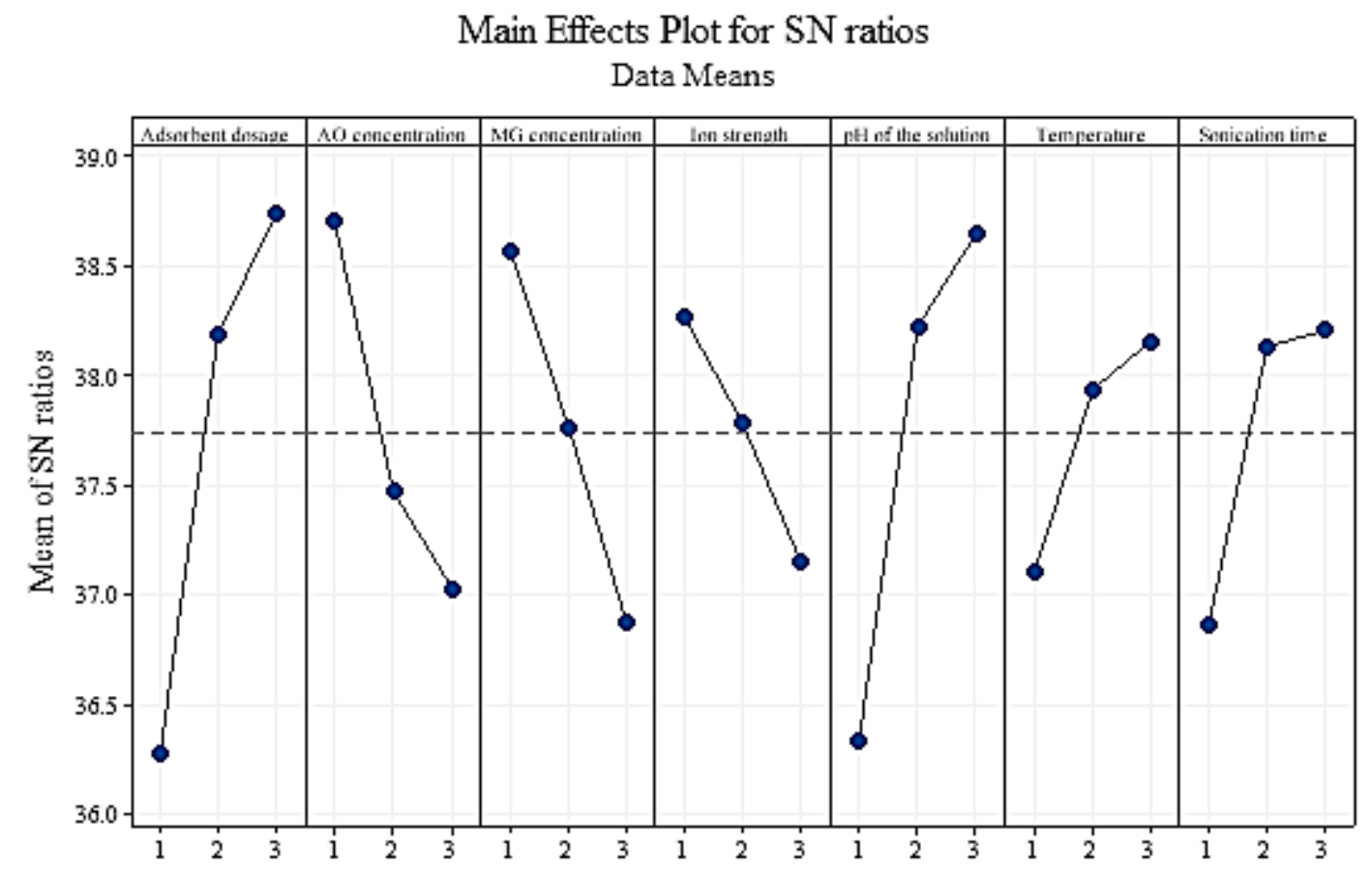

Signal-to-noise: Larger is better

Fig 3. Signal to Noise Ratios for removal MG and AO.

Table 4. Response Table for Signal to Noise Ratios for MG and AO.

\begin{tabular}{llllllll}
\hline Level & $\begin{array}{l}\text { Adsorbent } \\
\text { dosage }(\mathrm{g})\end{array}$ & $\begin{array}{l}\text { AO concentration } \\
\left(\mathrm{mg} \mathrm{L}^{-1}\right)\end{array}$ & $\begin{array}{l}\text { MG concentration } \\
\left(\mathrm{mg} \mathrm{L}^{-1}\right)\end{array}$ & $\begin{array}{l}\text { Ionic strength } \\
(\mathrm{w} / \mathrm{v} \%)\end{array}$ & $\begin{array}{l}\mathrm{pH} \text { of the } \\
\text { solution }\end{array}$ & $\begin{array}{l}\text { Temperature } \\
\left({ }^{\circ} \mathrm{C}\right)\end{array}$ & $\begin{array}{l}\text { Sonication time } \\
(\mathrm{min})\end{array}$ \\
\hline 1 & 36.26 & 38.69 & 38.55 & 38.25 & 36.33 & 37.11 & 36.87 \\
2 & 38.19 & 37.47 & 37.77 & 37.79 & 38.23 & 37.94 & 38.13 \\
3 & 38.74 & 37.03 & 36.87 & 37.16 & 38.63 & 38.14 & 38.19 \\
Delta & 2.48 & 1.65 & 1.67 & 1.09 & 2.30 & 1.03 & 1.32 \\
Rank & 1 & 4 & 3 & 6 & 2 & 7 & 5 \\
\hline
\end{tabular}

\subsection{Significant variable optimization by RSM}

In this section, Design Expert statistical software version 10 was used to execute the CCD design and analyze the resulting data. Software output includes main effects, their interactions, quadratic equation, and statistical graphs. To perform experiments by the CCD method, the software designed 32 experiments. Table 5 shows the order of these 32 experiments. Method of analysis in section 2.4. Analytical methods are provided. The answer to each row of the experiment is also given. 
Table 5. CCD design of variables and their corresponding experimental and predicted removal of MG and AO.

\begin{tabular}{|c|c|c|c|c|c|c|c|c|c|}
\hline \multirow{3}{*}{$\begin{array}{l}\text { Run } \\
\text { No. }\end{array}$} & \multicolumn{5}{|c|}{ Variables } & \multicolumn{4}{|c|}{ Responses } \\
\hline & \multirow[b]{2}{*}{ A } & \multirow[b]{2}{*}{$\mathrm{B}$} & \multirow[b]{2}{*}{$\mathrm{C}$} & \multirow[b]{2}{*}{$\mathrm{D}$} & \multirow[b]{2}{*}{$\mathrm{E}$} & \multicolumn{2}{|l|}{$\% \mathrm{R}_{\mathrm{MG}}$} & \multicolumn{2}{|l|}{$\% \mathrm{R}_{\mathrm{AO}}$} \\
\hline & & & & & & Actual & Predicted & Actual & Predicted \\
\hline 1 & 350 & 6 & 8 & 4 & 12 & 63.56 & 63.75 & 73.44 & 73.28 \\
\hline 2 & 350 & 10 & 8 & 4 & 6 & 92.97 & 93.56 & 87.73 & 87.81 \\
\hline 3 & 300 & 8 & 2 & 6 & 9 & 84.50 & 83.88 & 90.62 & 90.89 \\
\hline 4 & 300 & 8 & 6 & 2 & 9 & 77.76 & 76.28 & 87.08 & 87.68 \\
\hline 5 & 300 & 4 & 6 & 6 & 9 & 29.18 & 29.49 & 38.37 & 38.97 \\
\hline 6 & 300 & 8 & 6 & 6 & 9 & 82.15 & 82.00 & 92.25 & 92.43 \\
\hline 7 & 250 & 6 & 4 & 4 & 12 & 57.62 & 57.92 & 61.59 & 61.28 \\
\hline 8 & 400 & 8 & 6 & 6 & 9 & 87.39 & 86.99 & 87.85 & 87.81 \\
\hline 9 & 300 & 12 & 6 & 6 & 9 & 62.91 & 61.99 & 79.23 & 78.35 \\
\hline 10 & 350 & 10 & 8 & 8 & 12 & 57.86 & 57.77 & 96.40 & 96.98 \\
\hline 11 & 250 & 6 & 8 & 4 & 6 & 34.29 & 34.53 & 43.91 & 43.67 \\
\hline 12 & 300 & 8 & 6 & 10 & 9 & 43.47 & 44.35 & 62.48 & 61.61 \\
\hline 13 & 300 & 8 & 6 & 6 & 15 & 84.06 & 83.95 & 89.73 & 89.33 \\
\hline 14 & 300 & 8 & 6 & 6 & 9 & 84.44 & 82.00 & 94.26 & 92.43 \\
\hline 15 & 350 & 10 & 4 & 4 & 12 & 98.68 & 99.33 & 99.03 & 99.04 \\
\hline 16 & 300 & 8 & 10 & 6 & 9 & 56.85 & 56.86 & 74.86 & 74.31 \\
\hline 17 & 200 & 8 & 6 & 6 & 9 & 54.17 & 53.96 & 48.06 & 47.82 \\
\hline 18 & 250 & 10 & 8 & 8 & 6 & 37.94 & 37.90 & 48.54 & 49.04 \\
\hline 19 & 300 & 8 & 6 & 6 & 9 & 80.94 & 82.00 & 90.69 & 92.43 \\
\hline 20 & 300 & 8 & 6 & 6 & 9 & 79.75 & 82.00 & 91.37 & 92.43 \\
\hline 21 & 350 & 6 & 4 & 8 & 12 & 85.39 & 85.15 & 62.28 & 62.29 \\
\hline 22 & 350 & 6 & 4 & 4 & 6 & 52.46 & 52.90 & 84.92 & 84.43 \\
\hline 23 & 300 & 8 & 6 & 6 & 9 & 82.73 & 82.00 & 93.07 & 92.43 \\
\hline 24 & 350 & 6 & 8 & 8 & 6 & 27.69 & 27.39 & 43.83 & 43.91 \\
\hline 25 & 250 & 6 & 8 & 8 & 12 & 46.09 & 45.65 & 45.99 & 46.25 \\
\hline 26 & 300 & 8 & 6 & 6 & 9 & 81.38 & 82.00 & 92.67 & 92.43 \\
\hline 27 & 350 & 10 & 4 & 8 & 6 & 58.07 & 58.23 & 78.46 & 78.71 \\
\hline 28 & 250 & 10 & 4 & 4 & 6 & 75.73 & 76.43 & 76.81 & 76.74 \\
\hline 29 & 300 & 8 & 6 & 6 & 3 & 58.76 & 58.27 & 74.43 & 74.55 \\
\hline 30 & 250 & 10 & 8 & 4 & 12 & 56.98 & 57.43 & 72.08 & 72.34 \\
\hline 31 & 250 & 10 & 4 & 8 & 12 & 56.35 & 56.37 & 64.13 & 64.56 \\
\hline 32 & 250 & 6 & 4 & 8 & 6 & 39.90 & 39.71 & 52.67 & 52.59 \\
\hline
\end{tabular}

(A: adsorbent dosage (g), B: $\mathrm{pH}$ of the solution, $\mathrm{C}: \mathrm{MG}$ concentration $\left(\mathrm{mg} \mathrm{L}^{-1}\right)$, D: AO concentration $\left(\mathrm{mg} \mathrm{L}^{-1}\right)$ and E: sonication time (min)).

A reliable method for evaluating the quality of a matched model is the use of analysis of variance (ANOVA). In ANOVA, the share of variance of each factor is compared with the variance caused by random errors in measurement. In fact, the significance of regression can be examined through this comparison. Significance of regression is performed by comparing the variance of the regression to the variance of the residuals with the Fisher distribution (Ftest). If this ratio is greater than the critical value of $\mathrm{F}$, the mathematical model is consistent with the experimental data. If the calculated p-value for each of the factors is less than 0.05 , it indicates the effectiveness of that factor, and if it is more than 0.05 , it means that the change of that factor has no effect on the values. The parameters for MG and AO dyes are given in Table 6. The correlation coefficients $\left(R^{2}\right)$ were 0.9983 and 0.9988 and adj- $R^{2}$ were 0.9953 and 
0.9967 for $\mathrm{MG}$ and $\mathrm{AO}$, respectively. High values of $\mathrm{R}^{2}$ and adj- $\mathrm{R}^{2}$ confirm the model's ability to make a convincing estimate of the response.

Table 6. Analysis of variance for the quadratic polynomial model for removal of MG and AO.

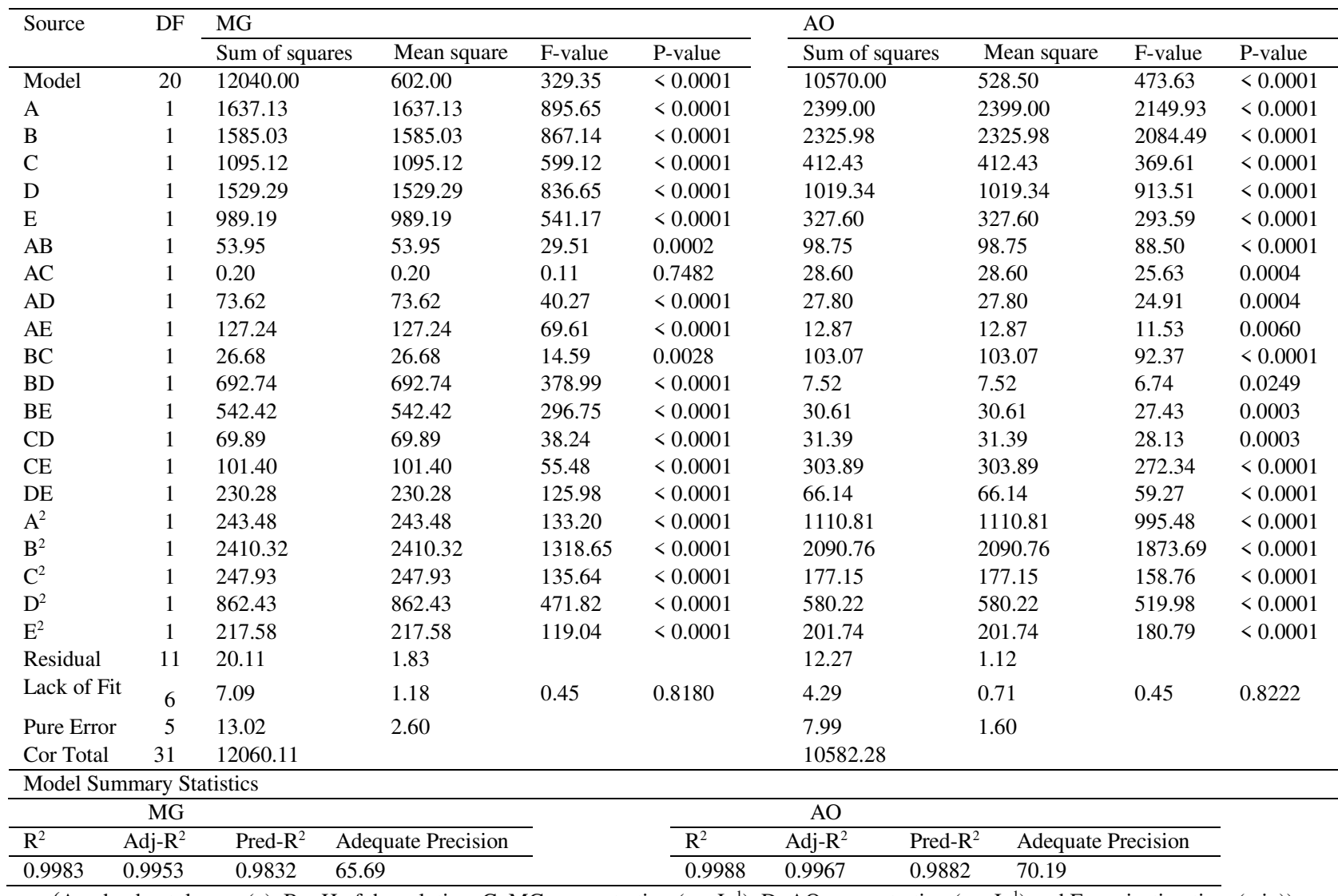

(A: adsorbent dosage (g), B: $\mathrm{pH}$ of the solution, C: MG concentration $\left(\mathrm{mg} \mathrm{L}^{-1}\right)$, D: AO concentration $\left(\mathrm{mg} \mathrm{L}^{-1}\right)$ and E: sonication time (min)).

As can be seen in Table 6, the value of $\mathrm{p}$ for linear and interaction factors is less than 0.05 . From the value of $\mathrm{p}$ related to nonconformity, it can be deduced that the equation obtained is consistent with the experimental data. The mathematical model was presented as a second-order polynomial relation in coded form (A, B, etc.) to describe each of the deletion efficiency responses $(\% \mathrm{R})$ for each of the dyes in Equations 4 and 5.

$\mathrm{R}_{\mathrm{MG}}=+82.00+8.26 * \mathrm{~A}+8.13 * \mathrm{~B}-6.75 * \mathrm{C}-7.98 * \mathrm{D}+6.42 * \mathrm{E}+1.84 * \mathrm{AB}+0.11 * \mathrm{AC}-2.14 * \mathrm{AD}+2.82 * \mathrm{AE}+1.29 * \mathrm{BC}-6.58 * \mathrm{BD}-$

$5.82 * \mathrm{BE}-2.09 * \mathrm{CD}-2.52 * \mathrm{CE}+3.79 * \mathrm{DE}-2.88 * \mathrm{~A}^{2}-9.06 * \mathrm{~B}^{2}-2.91 * \mathrm{C}^{2}-5.42 * \mathrm{D}^{2}-2.72 * \mathrm{E}^{2}$ 
$\% \mathrm{R}_{\mathrm{AO}}=+92.43+10.00 * \mathrm{~A}+9.84 * \mathrm{~B}-4.15 * \mathrm{C}-6.52 * \mathrm{D}+3.69 * \mathrm{E}+2.48 * \mathrm{AB}+1.34 * \mathrm{AC}-1.32 * \mathrm{AD}+0.90 * \mathrm{AE}+2.54 * \mathrm{BC}+0.69 * \mathrm{BD}$

In Equations 4 and 5, the parameters of adsorbent amount (A), pH of solution (B), MG concentration (C), AO concentration (D), and sonication time (E).

a)

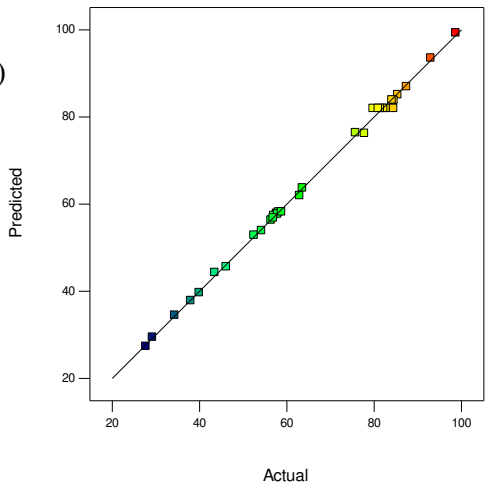

d)

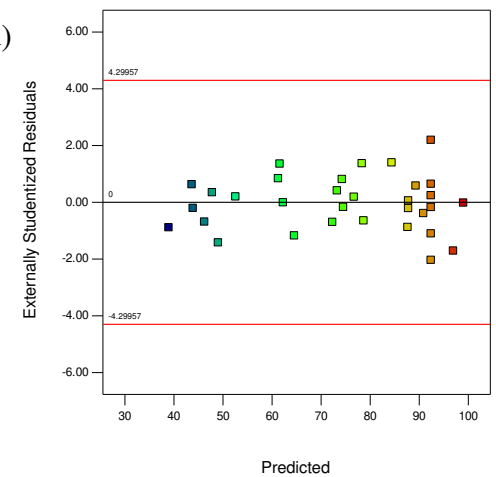

b)
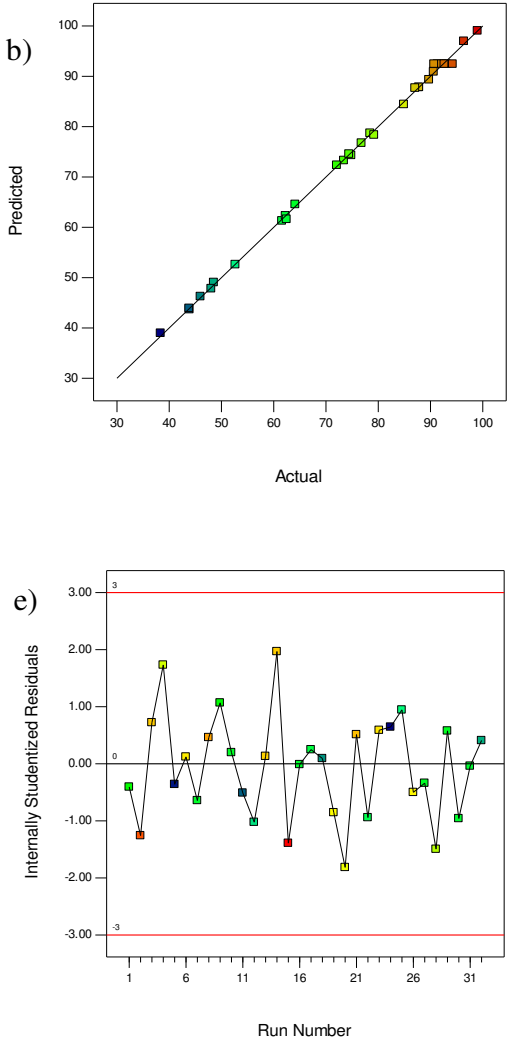

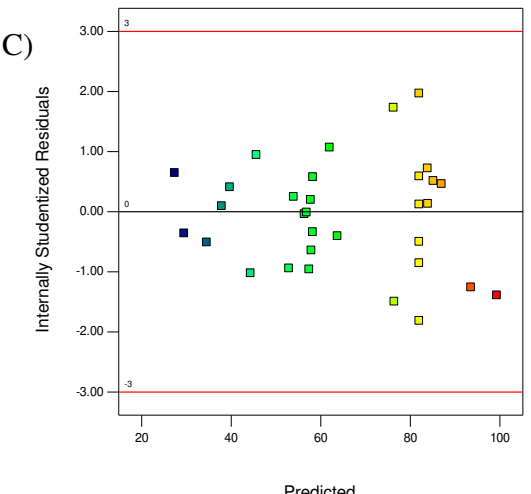

f)

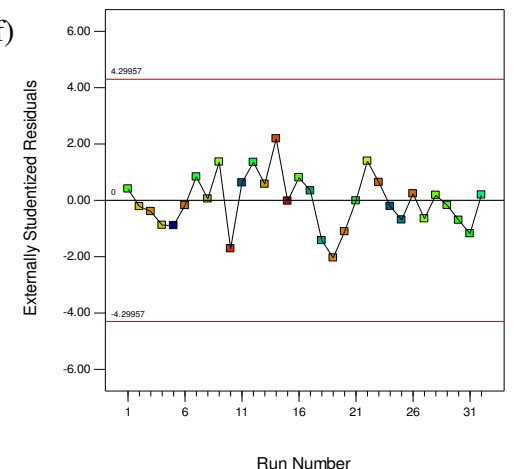

Fig. 4. Plot of predicted value versus actual value (a): MG and (b): AO, plots of residuals for removal of (c and e): MG and (d and f): AO.

Residual diagrams help to interpret the results accurately. Assuming that the errors are normally distributed and independent of each other, residual probability diagrams (Figs 4a and 4b) are an important diagnostic tool to identify and explain systematic deviations. Also, the residual probability graph also shows that the variance of the error is homogeneous [27]. In this diagram, the closer the points are to the line, the less error there is. As shown in Figs 4a and $4 \mathrm{~b}$ are points close to the line. In Figs $4 \mathrm{c}$ to $4 \mathrm{f}$, the better the distribution of points at the top and bottom of the 
axis is the same (i.e. the probability of positive and negative error is the same and the test error is not a systematic error). As shown in Figs 4c to 4f, there is no systematic error.

Fig. 5 shows the three-dimensional diagrams of the interaction effect. Three-dimensional diagrams of surface response are a function of two independent parameters that keep all other parameters at constant levels. These diagrams can provide information about the relationship between the two parameters and are useful in understanding the main effects and interaction effects of the two parameters. Figure 5a shows the interaction of the two parameters of solution $\mathrm{pH}$ and the amount of adsorbent on the amount of MG dye removal. The MG dye removal goes up with increasing $\mathrm{pH}$ of the solution and increasing the amount of adsorbent. At pHs higher than $\mathrm{pH}_{\mathrm{PZC}}$, which is 6.5 for $\mathrm{NaX}$ nanozeolites, the surface charge of the nanoparticles is negative. Thus, the adsorption of positively charged dye molecules due to electrostatic attraction increases. On the other hand, increasing the amount of adsorbent provides more adsorption sites for dye molecules to be adsorbed on the adsorbent surface. Therefore, the interaction of these two parameters, which causes the positive surface of nanoparticles and increases the adsorption sites, increases the adsorption. As shown in Figures 5b and 5c, the amount of dye removal decreases with an increasing dye concentration of MG and AO. Decreasing the removal percentage at higher concentrations is due to the increase in dye concentration relative to the number of initial moles of dye available to the surface area. For a given amount of adsorbent, the total number of active sites available is constant, and as a result, the same amount of site absorbs the analyte, so as the initial dye concentration increases, the removal percentage decreases. Figure 5d shows the effect of sonication time on the amount of AO dye removal. As it is known, with increasing sonication time, the amount of dye removal should increase. This is because with increasing time, there is more opportunity for the dye and adsorbent molecules to be exposed. 

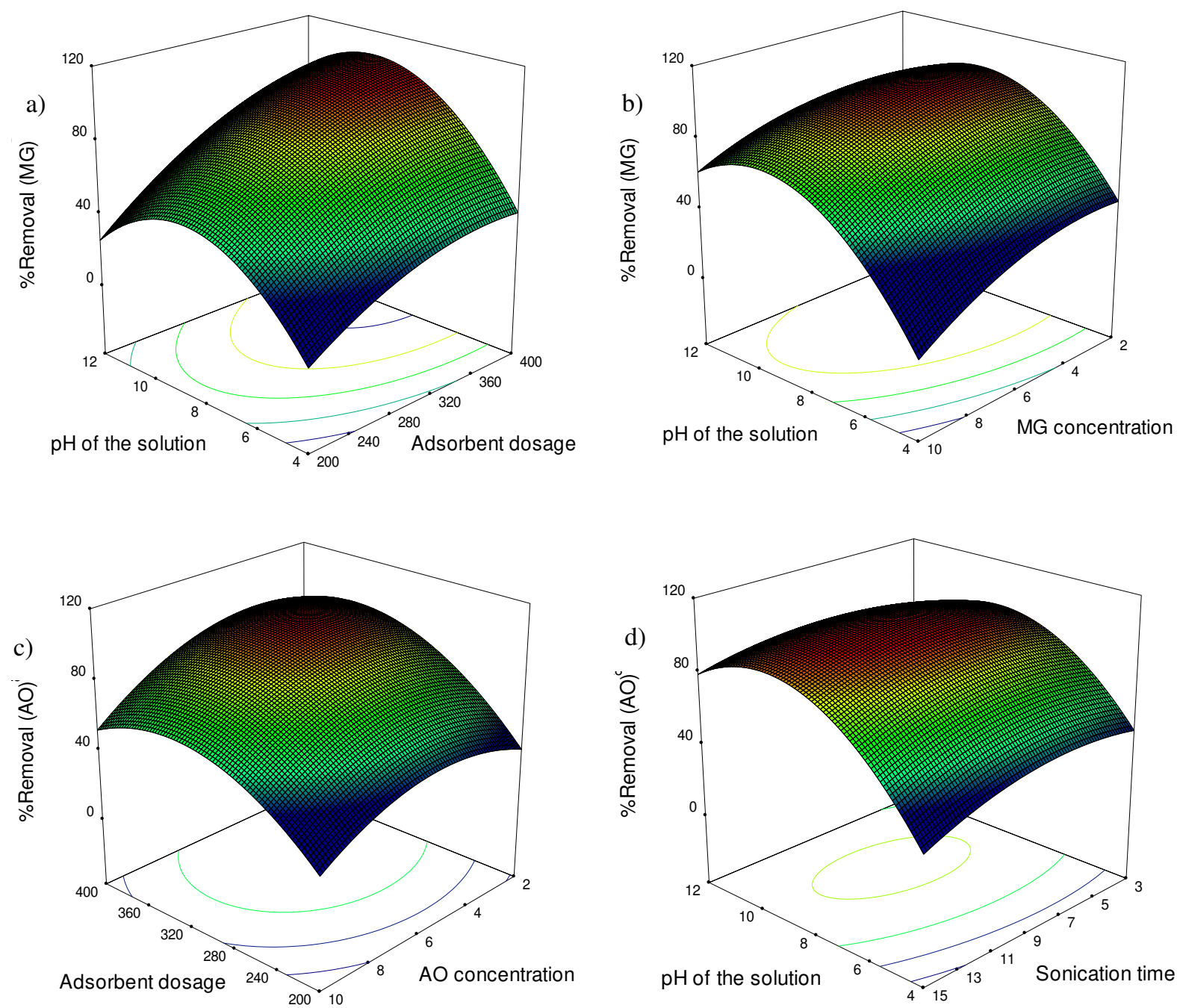

Fig. 5. Response surface plots of removal of (a and b): $\mathrm{MG}$ and (c and d): AO.

\subsection{Optimization}

Optimization in chemistry is used effectively and economically to reduce cost and time in multi-response methods.

For this reason, following investigating the factors affecting the removal of MG and AO dyes by the Taguchi method, the conditions for removing the dye from the solution by RSM were optimized. According to the experiments performed in Taguchi design, the most important factors affecting the removal of MG and AO dyes in the method are solution $\mathrm{pH}$, adsorbent mass, sonication time, the concentration of $\mathrm{MG}$ and $\mathrm{AO}$ dyes. These items were evaluated as the main factors (independent variables) in the RSM statistical design. The optimal values of each parameter were presented by the software and the relevant tests were performed. All stages of the experiment were carried out 
according to the Analytical methods section. Optimal values and test results are shown in Table S2. It is observed that more than $99 \%$ of both dyes are removed from the solution by NaX nanozeolites in optimal conditions.

\subsection{Application to real samples}

In order to study the efficiency of the method for the analysis of real samples, NaX nanozeolites were used as adsorbents to remove MG and $\mathrm{AO}$ from fish farms, tap water, and drinking water samples. For this reason, tests were performed in optimal conditions, in accordance with the method mentioned in Section 2.4. Analytical methods. Environmental water samples were used instead of distilled water. After spectrophotometric determination of the remaining amount of dye, the percentage of simultaneous removal for MG and AO dyes was more than \%98.1 in environmental water samples (Table S3). This means that $\mathrm{NaX}$ nanozeolites can remove significant amounts of MG and $\mathrm{AO}$ from environmental water samples.

\subsection{Interference studies}

After obtaining the optimal conditions of effective parameters for removing the synchrony of MG and AO dyes, interference studies were carried out to evaluate the selectivity of the method. In order to investigate the disturbance effect of different ions, different concentrations of disturbing ions were added to the solution and the steps were taken according to the method described in Section 2.4. Also, Analytical methods were applied. The results are shown in Table S4. If the signal obtained in the presence of the disturbing ion differs by $\pm 5 \%$ from the signal in the absence of the disturbing ion, it indicates the degree of disturbance of the species on the decomposition signal. To determine the tolerance limit of the disturbing ion, a lower concentration of that species is examined to give an error value of $\pm 5 \%$. According to the results, by adding almost high amounts of ions, no interference was observed on the decomposition signal. In this study and in optimal conditions, the rate of dye removal in the presence of other ions was above $\% 95$, which indicates the proper selectivity of $\mathrm{NaX}$ nanozeolites to both dyes despite the competitive effect of other ions.

\subsection{Desorption and reusability studies}


The reuse of adsorbent could be considered as one of the important economic parameters. Therefore, the recyclability of $\mathrm{NaX}$ nanozeolites during the MG and $\mathrm{AO}$ adsorption process was evaluated. In this study, the NaX nanozeolites used were washed with a small amount of methanol and then dried for reuse in a vacuum-oven. Finally, the amount of adsorption in each cycle was measured by spectrophotometry. The results in Figure 6 show that up to 5 cycles, the adsorption efficiency decreases slightly. In general, this reduction can be due to adsorption degradation during adsorption-desorption cycles.

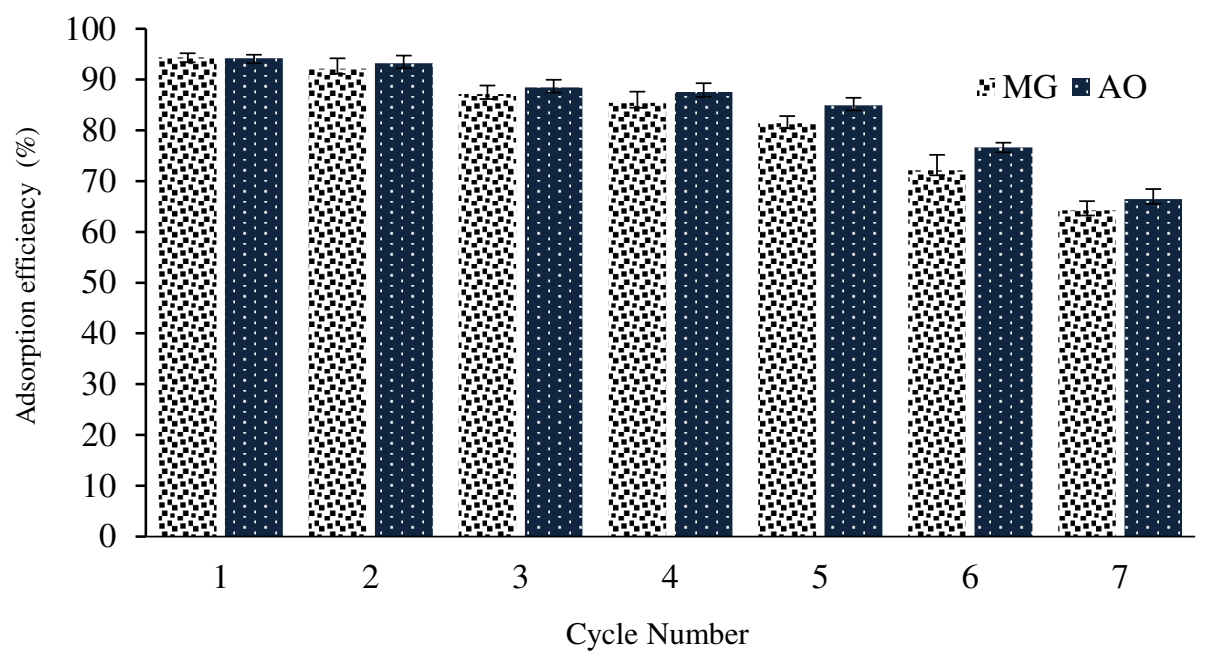

Fig. 6. Effect of regeneration cycles on adsorption of dyes onto $\mathrm{NaX}$ nanozeolites.

\subsection{Comparison of adsorbents}

The efficiency of the proposed method was evaluated with other methods for removing MG and AO dyes. The results are given in Table 7. The results of this study showed that the developed method, compared to other methods, provides high removal of contamination (dye) in a short time from water samples. This method also has other advantages such as the low number of tests, low operating costs, and optimization in the best possible way to achieve the highest efficiency (percentage of paint removal).

Table 7. Comparison of the NaX nanozeolites with other adsorbents for removal MG and AO. 


\begin{tabular}{|c|c|c|c|c|c|c|c|}
\hline Adsorbent & Dye & $\begin{array}{l}\text { Adsorbent } \\
\text { dosage }\end{array}$ & Concentration & $\mathrm{pH}$ & Time & $\begin{array}{l}\text { Removal } \\
\text { / adsorption capacity }\end{array}$ & Ref. \\
\hline Fe3O4/ $\beta$-cyclodextrin-graphene oxide & MG & $5 \mathrm{mg}$ & $100 \mathrm{mg} \mathrm{L}^{-1}$ & 7 & $2 \mathrm{~h}$ & $\% 98$ & {$[48]$} \\
\hline Amberlite XAD-4 (polymeric resin) & MG & $1.5 \mathrm{~g}$ & $10 \mathrm{mg} \mathrm{L}^{-1}$ & 10 & $10 \mathrm{~min}$ & $\% 93.12$ & {$[49]$} \\
\hline Sodium alginate-coated $\mathrm{Fe} 3 \mathrm{O} 4$ & MG & $0.03 \mathrm{~g}$ & 10 & 7 & $20 \min$ & $47.84 \mathrm{mg} \mathrm{g}^{-1}$ & {$[50]$} \\
\hline $\begin{array}{l}\text { Polyacrylamide-g } \\
\text { Chitosan } \gamma \text {-Fe2O3 }\end{array}$ & MG & $0.75 \mathrm{~g}$ & $60 \mathrm{mg} \mathrm{L}^{-1}$ & 6 & $170 \mathrm{~min}$ & $\% 77$ & {$[51]$} \\
\hline $\mathrm{Fe} 3 \mathrm{O} 4 /$ activated carbon & MG & $0.1 \mathrm{~g}$ & $100 \mathrm{mg} \mathrm{L}^{-1}$ & 6 & $1 \mathrm{~h}$ & $\% 96$ & {$[52]$} \\
\hline NaX nanozeolites & MG & $347 \mathrm{mg}$ & $4 \mathrm{mg} \mathrm{L}^{-1}$ & 8 & $11.5 \mathrm{~min}$ & $\% 99.07$ & this work \\
\hline $\begin{array}{l}\text { Fe3O4/melamine-rich covalent } \\
\text { organic polymer }\end{array}$ & $\mathrm{AO}$ & $12 \mathrm{mg}$ & $10 \mathrm{mg} \mathrm{L}^{-1}$ & 6.5 & $4 \mathrm{~min}$ & $107.11 \mathrm{mg} \mathrm{g}^{-1}$ & {$[53]$} \\
\hline Multiwall carbon nanotubes & $\mathrm{AO}$ & $40 \mathrm{mg}$ & $10 \mathrm{mg} \mathrm{L}^{-1}$ & 7 & $1 \mathrm{~h}$ & $\% 97$ & {$[54]$} \\
\hline $\mathrm{M} \mathrm{C}^{\mathrm{a}}$ & $\mathrm{AO}$ & $16 \mathrm{mg}$ & $5 \mathrm{mg} \mathrm{L}^{-1}$ & 9.5 & $8 \mathrm{~min}$ & $17.95 \mathrm{mg} \mathrm{g}^{-1}$ & {$[55]$} \\
\hline Diospyros lotus seed powder & $\mathrm{AO}$ & $0.1 \mathrm{~g}$ & $20 \mathrm{mg} \mathrm{L}^{-1}$ & 6 & $2 \mathrm{~h}$ & $26.95 \mathrm{mg} \mathrm{g}^{-1}$ & {$[56]$} \\
\hline Sugarcane bagasse & $\mathrm{AO}$ & $0.05 \mathrm{~g}$ & $200 \mathrm{mg} \mathrm{L}^{-1}$ & 8 & $9 \mathrm{~h}$ & $682.8 \mathrm{mg} \mathrm{g}^{-1}$ & {$[57]$} \\
\hline Aca-NaAlg-cl-poly(AA) & $\mathrm{AO}$ & 0.4 & $16 \mathrm{mg} \mathrm{L}^{-1}$ & 9 & $20 \mathrm{~h}$ & $\% 97.49$ & {$[58]$} \\
\hline $\begin{array}{l}\text { Sodium dodecyl sulfate (SDS) } \\
\text { functionalized magnetite } \\
\text { nanoparticles }\end{array}$ & $\mathrm{AO}$ & $20 \mathrm{mg}$ & $20 \mathrm{mg} \mathrm{L}^{-1}$ & 6.5 & $40 \min$ & $\% 74$ & {$[59]$} \\
\hline NaX nanozeolites & $\mathrm{AO}$ & $347 \mathrm{mg}$ & $4 \mathrm{mg} \mathrm{L}^{-1}$ & 8 & $11.5 \mathrm{~min}$ & $\% 99.61$ & this work \\
\hline
\end{tabular}

\section{Conclusion}

The efficiency of NaX nanozeolites for simultaneous removal of malachite green (MG) and auramine-O (AO) dyes from aqueous solutions was investigated. The synthesized nanosorbents were characterized using SEM and XRD. The most important variables affecting the dye removal process were determined by the Taguchi method. These effective variables included solution $\mathrm{pH}$, adsorbent mass, sonication time, $\mathrm{MG}$, and $\mathrm{AO}$ dye concentrations and were optimized and modeled by CCD based on the RSM method. The optimal conditions obtained by RSM modeling included pH 8 , ultrasound time of 11.5 minutes, an absorbent dose of $347 \mathrm{mg}$, and concentration of both dyes $4 \mathrm{mg} \mathrm{L}^{-1}$, and the highest dye removal (more than \%99) was obtained for both dyes. Quadratic models for dye determination were statistically compared with values of $\mathrm{R}^{2}>0.99$ and $\mathrm{p}<0.0001$, and the results showed that both models have reasonable accuracy. The results obtained for adsorption-desorption experiments showed that the adsorbent can be reused up to 5 times without a significant reduction in the percentage of dye removal. The efficiency of the method for analyzing real samples containing MG and AO dyes also showed that the developed method can remove high amounts of dye contamination (\%98.1) from complex samples. 


\section{AUTHOR CONTRIBUTIONS}

S.S. conceived and planned the experiments. S.S. and S.S. carried out the experiments. Sh.S. contributed to the interpretation of the results. S.S. took the lead in writing the manuscript. All authors discussed the results and contributed to the final manuscript.

\section{ACKNOWLEDGEMENT}

This research was supported by Payame Noor University.

\section{COMPETING INTERESTS}

The authors declare that there is no conflict of interests regarding the publication of this paper.

\section{DATA AVAILABILITY}

The authors declare that [the/all other] data supporting the findings of this study are available within the paper [and its supplementary information files].

\section{References}

[1] Lakkaboyana, S., Soontarapa, K., Asmel, N. et al. (2021). Synthesis and characterization of Cu(OH)2-NWs-PVAAC Nano-composite and its use as an efficient adsorbent for removal of methylene blue. Scientific reports, 11, 5686.

[2] Shojaei, S., Shojaei, S., Nouri, A. et al. (2021). Application of chemometrics for modeling and optimization of ultrasound-assisted dispersive liquid-liquid microextraction for the simultaneous determination of dyes. npj Clean Water 4, 23. 
[3] Moattari, R. M., \& Mohammadi, T. (2021). Hybrid Adsorbents for Dye Removal from Wastewater. In Green Adsorbents to Remove Metals, Dyes and Boron from Polluted Water (pp. 405-451). Springer, Cham.

[4] Ismail, M., Akhtar, K., Khan, M. I., Kamal, T., Khan, M. A., M Asiri, A., ... \& Khan, S. B. (2019). Pollution, toxicity and carcinogenicity of organic dyes and their catalytic bio-remediation. Current pharmaceutical design, 25(34), 3645-3663.

[5] Rahman, I. A., Saad, B., Shaidan, S., \& Rizal, E. S. (2005). Adsorption characteristics of malachite green on activated carbon derived from rice husks produced by chemical-thermal process. Bioresource technology, 96(14), $1578-1583$.

[6] Sadat, S. A., Ghaedi, A. M., Panahimehr, M., Baneshi, M. M., Vafaei, A., \& Ansarizadeh, M. (2019). Rapid roomtemperature synthesis of cadmium zeolitic imidazolate framework nanoparticles based on 1, 1'-carbonyldiimidazole as ultra-high-efficiency adsorbent for ultrasound-assisted removal of malachite green dye. Applied Surface Science, 467, 1204-1212.

[7] Sreekanth, T.V.M., Nagajyothi, P.C., Reddy, G.R. et al. (2019). Urea assisted ceria nanocubes for efficient removal of malachite green organic dye from aqueous system. Scientific reports, 9, 14477.

[8] de Jesus Azevedo, C. C., de Oliveira, R., Suares-Rocha, P., Sousa-Moura, D., Li, A. T., Grisolia, C. K., ... \& Montagner, C. C. (2021). Auramine dyes induce toxic effects to aquatic organisms from different trophic levels: an application of predicted non-effect concentration (PNEC). Environmental Science and Pollution Research, 28(2), 1866-1877.

[9] Pinto, A. H., Taylor, J. K., Chandradat, R., Lam, E., Liu, Y., Leung, A. C., ... \& Sunasee, R. (2020). Wood-based cellulose nanocrystals as adsorbent of cationic toxic dye, Auramine O, for water treatment. Journal of Environmental Chemical Engineering, 8(5), 104187.

[10] Shindhal, T., Rakholiya, P., Varjani, S., Pandey, A., Ngo, H. H., Guo, W., ... \& Taherzadeh, M. J. (2021). A critical review on advances in the practices and perspectives for the treatment of dye industry wastewater. Bioengineered, 12(1), 70-87. 
[11] Jia, Y., Ding, L., Ren, P., Zhong, M., Ma, J., \& Fan, X. (2020). Performances and mechanism of methyl orange and Congo red adsorbed on the magnetic ion-exchange resin. Journal of Chemical \& Engineering Data, 65(2), 725736.

[12] Hasanzadeh, M., Simchi, A., \& Far, H. S. (2020). Nanoporous composites of activated carbon-metal organic frameworks for organic dye adsorption: Synthesis, adsorption mechanism and kinetics studies. Journal of Industrial and Engineering Chemistry, 81, 405-414.

[13] Jawad, A. H., \& Abdulhameed, A. S. (2020). Mesoporous Iraqi red kaolin clay as an efficient adsorbent for methylene blue dye: adsorption kinetic, isotherm and mechanism study. Surfaces and Interfaces, 18, 100422.

[14] Liu, Y., Zhu, W., Guan, K., Peng, C., \& Wu, J. (2018). Freeze-casting of alumina ultra-filtration membranes with good performance for anionic dye separation. Ceramics International, 44(10), 11901-11904.

[15] Wang, J., Zhang, T., Mei, Y., \& Pan, B. (2018). Treatment of reverse-osmosis concentrate of printing and dyeing wastewater by electro-oxidation process with controlled oxidation-reduction potential (ORP). Chemosphere, 201, 621-626.

[16] Tan, Y. J., Sun, L. J., Li, B. T., Zhao, X. H., Yu, T., Ikuno, N., ... \& Hu, H. Y. (2017). Fouling characteristics and fouling control of reverse osmosis membranes for desalination of dyeing wastewater with high chemical oxygen demand. Desalination, 419, 1-7.

[17] El-Sayed, M. E. (2020). Nanoadsorbents for water and wastewater remediation. Science of The Total Environment, 139903.

[18] Soliman, N. K., \& Moustafa, A. F. (2020). Industrial solid waste for heavy metals adsorption features and challenges; a review. Journal of Materials Research and Technology, 9(5), 10235-10253.

[19] Rápó, E., Aradi, L. E., Szabó, Á., Posta, K., Szép, R., \& Tonk, S. (2020). Adsorption of remazol brilliant violet5R textile dye from aqueous solutions by using eggshell waste biosorbent. Scientific reports, 10(1), 1-12.

[20] Tang, S. H., \& Zaini, M. A. A. (2020). Development of activated carbon pellets using a facile low-cost binder for effective malachite green dye removal. Journal of Cleaner Production, 253, 119970. 
[21] Saja, S., Bouazizi, A., Achiou, B., Ouaddari, H., Karim, A., Ouammou, M., ... \& Younssi, S. A. (2020). Fabrication of low-cost ceramic ultrafiltration membrane made from bentonite clay and its application for soluble dyes removal. Journal of the European Ceramic Society, 40(6), 2453-2462.

[22] Bouhadjra, K., Lemlikchi, W., Ferhati, A., \& Mignard, S. (2021). Enhancing removal efficiency of anionic dye (Cibacron blue) using waste potato peels powder. Scientific reports, 11(1), 1-10.

[23] Mittal, H., Babu, R., Dabbawala, A. A., Stephen, S., \& Alhassan, S. M. (2020). Zeolite-Y incorporated karaya gum hydrogel composites for highly effective removal of cationic dyes. Colloids and Surfaces A: Physicochemical and Engineering Aspects, 586, 124161.

[24] Song, I., Lee, H., Jeon, S. W., Ibrahim, I. A., Kim, J., Byun, Y., .. \& Kim, D. H. (2021). Simple physical mixing of zeolite prevents sulfur deactivation of vanadia catalysts for NO x removal. Nature communications, 12(1), 1-9.

[25] Radoor, S., Karayil, J., Parameswaranpillai, J., \& Siengchin, S. (2020). Removal of anionic dye Congo red from aqueous environment using polyvinyl alcohol/sodium alginate/ZSM-5 zeolite membrane. Scientific reports, 10(1), 115.

[26] Santillán, J. M., Arboleda, D. M., Muraca, D., Schinca, D. C., \& Scaffardi, L. B. (2020). Highly fluorescent few atoms silver nanoclusters with strong photocatalytic activity synthesized by ultrashort light pulses. Scientific Reports, 10(1), 1-13.

[27] Oenema, J., Harmel, J., Vélez, R. P., Meijerink, M. J., Eijsvogel, W., Poursaeidesfahani, A., ... \& De Jong, K. P. (2020). Influence of Nanoscale Intimacy and Zeolite Micropore Size on the Performance of Bifunctional Catalysts for n-Heptane Hydroisomerization. ACS catalysis, 10(23), 14245-14257.

[28] Radoor, S., Karayil, J., Jayakumar, A., Parameswaranpillai, J., \& Siengchin, S. An efficient removal of malachite green dye from aqueous environment using ZSM-5 zeolite/polyvinyl alcohol/carboxymethyl cellulose/sodium alginate bio composite. Journal of Polymers and the Environment, 1-14.

[29] Sivalingam, S., \& Sen, S. (2020). Rice husk ash derived nanocrystalline ZSM-5 for highly efficient removal of a toxic textile dye. Journal of Materials Research and Technology, 9(6), 14853-14864. 
[30] Sivalingam, S., \& Sen, S. (2018). Rapid ultrasound assisted hydrothermal synthesis of highly pure nanozeolite X from fly ash for efficient treatment of industrial effluent. Chemosphere, 210, 816-823.

[31] Fraiese, A., Cesaro, A., Belgiorno, V., Sanromán, M. A., Pazos, M., \& Naddeo, V. (2020). Ultrasonic processes for the advanced remediation of contaminated sediments. Ultrasonics Sonochemistry, 67, 105171.

[32] Sricharoen, P., Kongsri, S., Kukusamude, C. et al. (2021). Ultrasound-irradiated synthesis of 3-mercaptopropyl trimethoxysilane-modified hydroxyapatite derived from fish-scale residues followed by ultrasound-assisted organic dyes removal. Scientific reports, 11, 5560 .

[33] Bhargava, N., Mor, R. S., Kumar, K., \& Sharanagat, V. S. (2020). Advances in application of ultrasound in food processing: A review. Ultrasonics Sonochemistry, 105293.

[34] Shojaei, S., Ardakani, M. A. H., \& Sodaiezadeh, H. (2020). Simultaneous optimization of parameters influencing organic mulch test using response surface methodology. Scientific reports, 10(1), 1-11.

[35] Stalin, B., Sudha, G. T., \& Ravichandran, M. (2020). Optimization of Powder Metallurgy Parameters for AA7072-MoO3 Composites through Taguchi Method. Materials Today: Proceedings, 22, 2622-2630.

[36] Park, R., Sridhar, V., \& Park, H. (2020). Taguchi method for optimization of reaction conditions in microwave glycolysis of waste PET. Journal of Material Cycles and Waste Management, 22(3), 664-672.

[37] Tan, Y. H., Abdullah, M. O., Nolasco-Hipolito, C., \& Zauzi, N. S. A. (2017). Application of RSM and Taguchi methods for optimizing the transesterification of waste cooking oil catalyzed by solid ostrich and chicken-eggshell derived CaO. Renewable Energy, 114, 437-447.

[38] Shojaei, S., Kalantari, Z., \& Rodrigo-Comino, J. (2020). Prediction of factors affecting activation of soil erosion by mathematical modeling at pedon scale under laboratory conditions. Scientific Reports, 10(1), 1-12.

[39] Jacyna, J., Kordalewska, M., \& Markuszewski, M. J. (2019). Design of Experiments in metabolomics-related studies: An overview. Journal of pharmaceutical and biomedical analysis, 164, 598-606.

[40] Shojaei, S., Nouri, A., Baharinikoo, L., Farahani, M. D., \& Shojaei, S. (2021). Removal of the hazardous dyes through adsorption over nanozeolite-X: Simultaneous model, design and analysis of experiments. Polyhedron, 196, 114995. 
[41] Matavos-Aramyan, S., Bagheri, G., \& Jazebizadeh, M. H. (2019). Pervaporation Separation of Toluene from Aqueous Solutions Using Nano-Based PEBA/NaX Mixed Matrix Membrane. Silicon, 11(4), 1725-1730.

[42] Shojaei, S., \& Shojaei, S. (2017). Experimental design and modeling of removal of Acid Green 25 dye by nanoscale zero-valent iron. Euro-Mediterranean Journal for Environmental Integration, 2(1), 1-7.

[43] Shojaei, S. (2019). Optimization of process variables by the application of response surface methodology for dye removal using nanoscale zero-valent iron. International Journal of Environmental Science and Technology, 16(8), 4601-4610.

[44] Mehr, H. V., Saffari, J., Mohammadi, S. Z., \& Shojaei, S. (2020). The removal of methyl violet 2B dye using palm kernel activated carbon: thermodynamic and kinetics model. International Journal of Environmental Science and Technology, 17(3), 1773-1782.

[45] Ging, R., Ding, Y., Li, M., Yang, C., Liu, H., \& Sun, Y. (2005). Utilization of powdered peanut hull as biosorbent for removal of anionic dyes from aqueous solutions. Dyes Pigments, 64(3), 187-92.

[46] Weng, C. H., \& Pan, Y. F. (2006). Adsorption characteristics of methylene blue from aqueous solution by sludge ash. Colloids and Surfaces A: Physicochemical and Engineering Aspects, 274(1-3), 154-162.

[47] El-Sayed, G. O. (2011). Removal of methylene blue and crystal violet from aqueous solutions by palm kernel fiber. Desalination, 272(1-3), 225-232.

[48] Wang, D., Liu, L., Jiang, X., Yu, J., \& Chen, X. (2015). Adsorption and removal of malachite green from aqueous solution using magnetic $\beta$-cyclodextrin-graphene oxide nanocomposites as adsorbents. Colloids and Surfaces A: Physicochemical and Engineering Aspects, 466, 166-173.

[49] Iqbal, M., \& Datta, D. (2020). Competitive removal of malachite green and Rhodamine-B using Amberlite-XAD4 impregnated with Aliquat 336: experimental and modelling studies. Separation Science and Technology, 55(3), 537553.

[50] Mohammadi, A., Daemi, H., \& Barikani, M. (2014). Fast removal of malachite green dye using novel superparamagnetic sodium alginate-coated $\mathrm{Fe} 3 \mathrm{O} 4$ nanoparticles. International journal of biological macromolecules, 69, 447-455. 
[51] Hasan, I., Bhatia, D., Walia, S., \& Singh, P. (2020). Removal of malachite green by polyacrylamide-g-chitosan $\gamma$-Fe2O3 nanocomposite-an application of central composite design. Groundwater for Sustainable Development, 11, 100378 .

[52] Altintig, E., Onaran, M., Sarı, A., Altundag, H., \& Tuzen, M. (2018). Preparation, characterization and evaluation of bio-based magnetic activated carbon for effective adsorption of malachite green from aqueous solution. Materials Chemistry and Physics, 220, 313-321.

[53] Shakeri, S., Rafiee, Z., \& Dashtian, K. (2020). Fe3O4-based melamine-rich covalent organic polymer for simultaneous removal of auramine O and rhodamine B. Journal of Chemical \& Engineering Data, 65(2), 696-705.

[54] Shabaan, O. A., Jahin, H. S., \& Mohamed, G. G. (2020). Removal of anionic and cationic dyes from wastewater by adsorption using multiwall carbon nanotubes. Arabian Journal of Chemistry, 13(3), 4797-4810.

[55] Firoozi, M., Rafiee, Z., \& Dashtian, K. (2020). New MOF/COF Hybrid as a Robust Adsorbent for Simultaneous Removal of Auramine O and Rhodamine B Dyes. ACS omega, 5(16), 9420-9428.

[56] Mahmud, T. (2018). Biosorption of Auramine O and Drimarene dyes from aqueous solutions using seed powder of Diospyros lotus. International Journal of Environment and Sustainability, 6(3).

[57] Martins, L. R., Rodrigues, J. A. V., Adarme, O. F. H., Melo, T. M. S., Gurgel, L. V. A., \& Gil, L. F. (2017). Optimization of cellulose and sugarcane bagasse oxidation: application for adsorptive removal of crystal violet and auramine-O from aqueous solution. Journal of colloid and interface science, 494, 223-241.

[58] Sharma, A. K., Kaith, B. S., Sharma, N., Bhatia, J. K., Tanwar, V., Panchal, S., \& Bajaj, S. (2019). Selective removal of cationic dyes using response surface methodology optimized gum acacia-sodium alginate blended superadsorbent. International journal of biological macromolecules, 124, 331-345.

[59] Muthukumaran, C., Sivakumar, V. M., Sumathi, S., \& Thirumarimurugan, M. (2020). Adsorptive Removal of Recalcitrant Auramine-O Dye by Sodium Dodecyl Sulfate Functionalized Magnetite Nanoparticles: Isotherm, Kinetics, and Fixed-Bed Column Studies. International Journal of Nanoscience, 19(01), 1950004. 
Figures

(a)<smiles>CN(C)c1ccc(C(=C2C=CC(=[N+](C)[O-])C=C2)c2ccccc2)cc1</smiles>

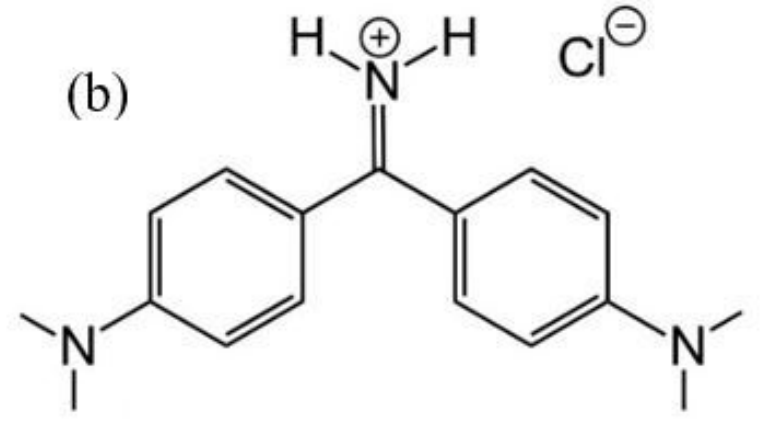

Figure 1

The chemical structure of (a) MG, and (b) AO.

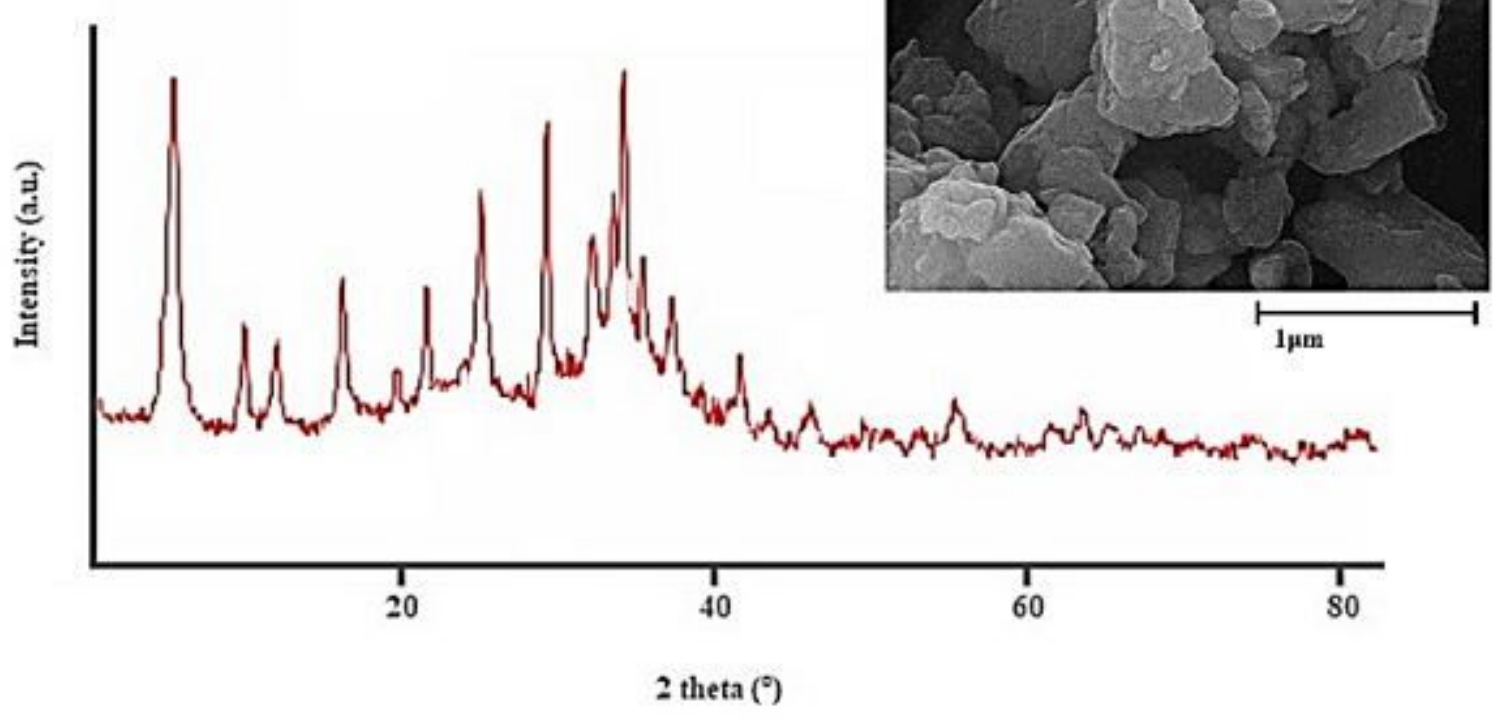

Figure 2

XRD pattern of nanozeolite-X. Inset shows SEM image of corresponding sample. 


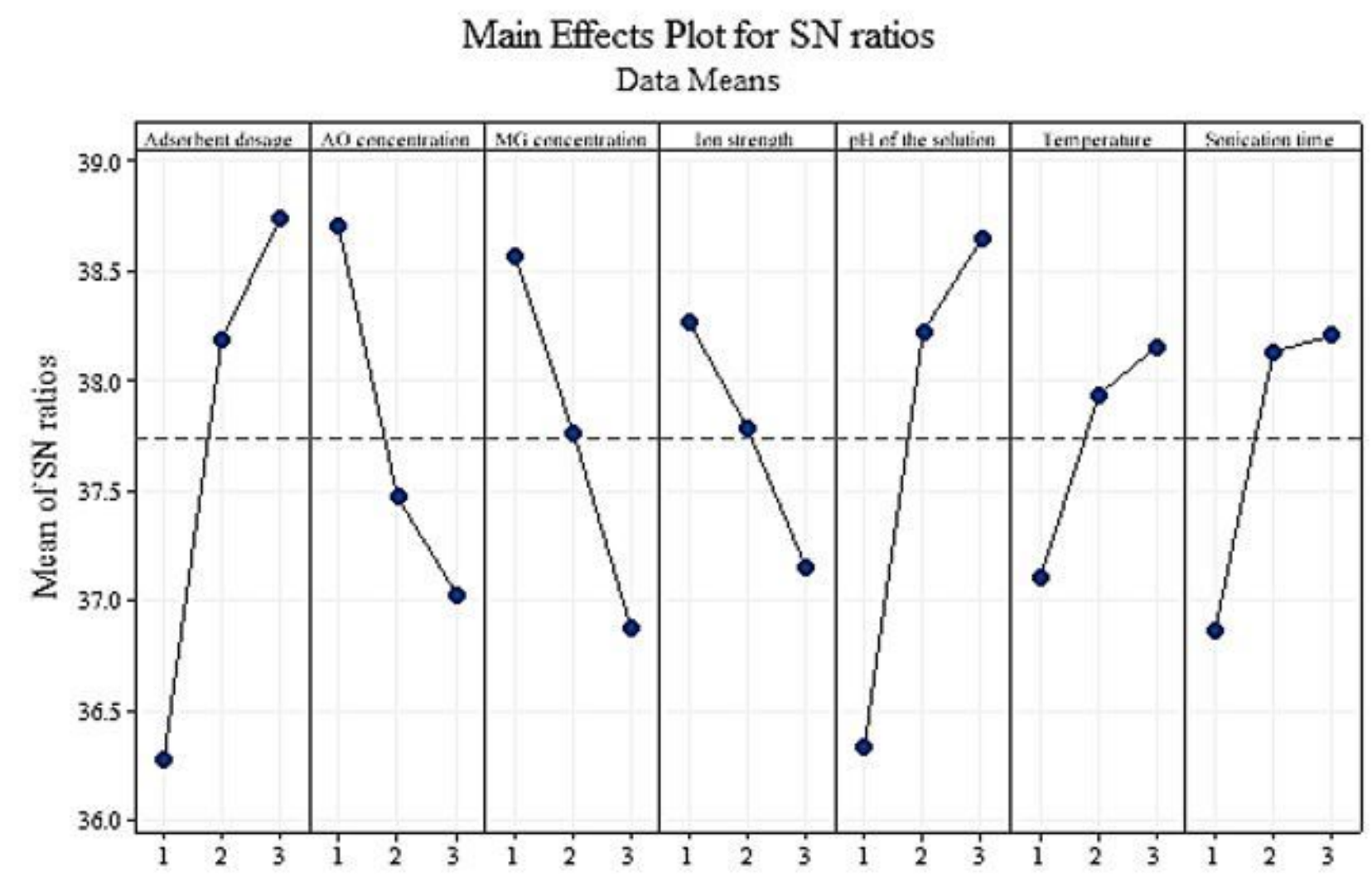

Signal-to-noise: Larger is better

Figure 3

Signal to Noise Ratios for removal MG and AO. 

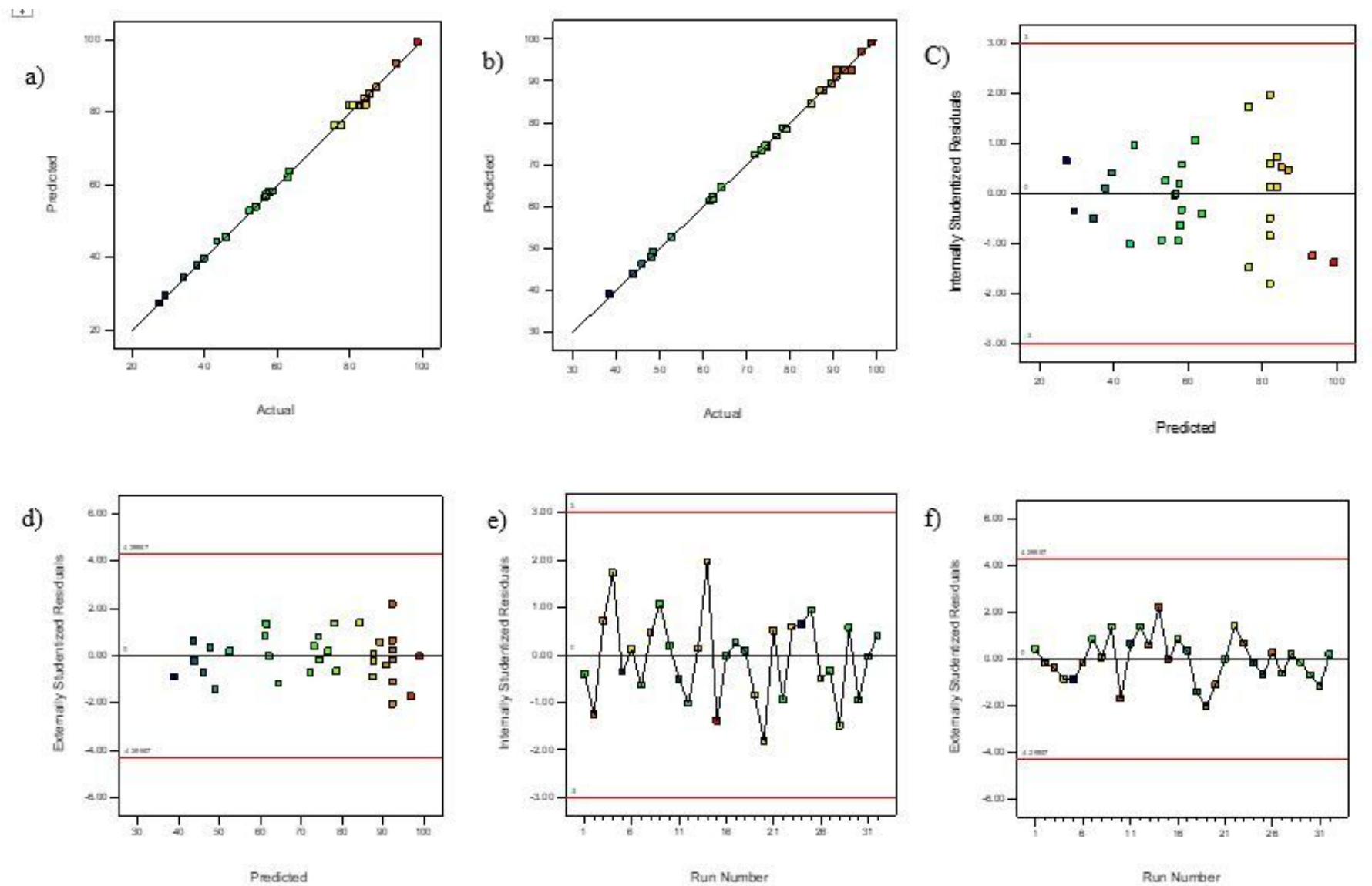

Figure 4

Plot of predicted value versus actual value (a): MG and (b): AO, plots of residuals for removal of (c and e): $M G$ and (d and f): AO. 

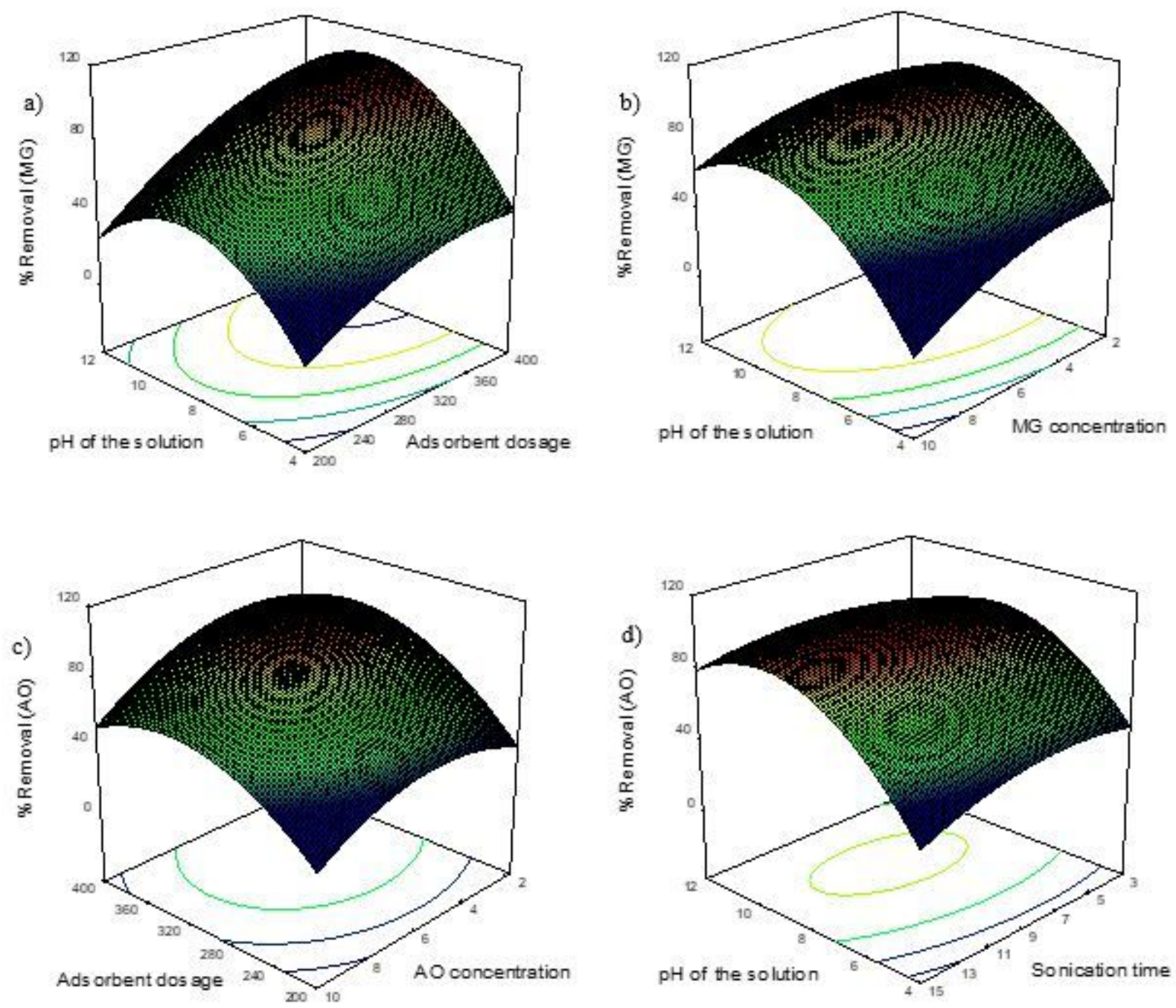

Figure 5

Response surface plots of removal of ( $a$ and $b$ ): $M G$ and (c and d): $A O$. 


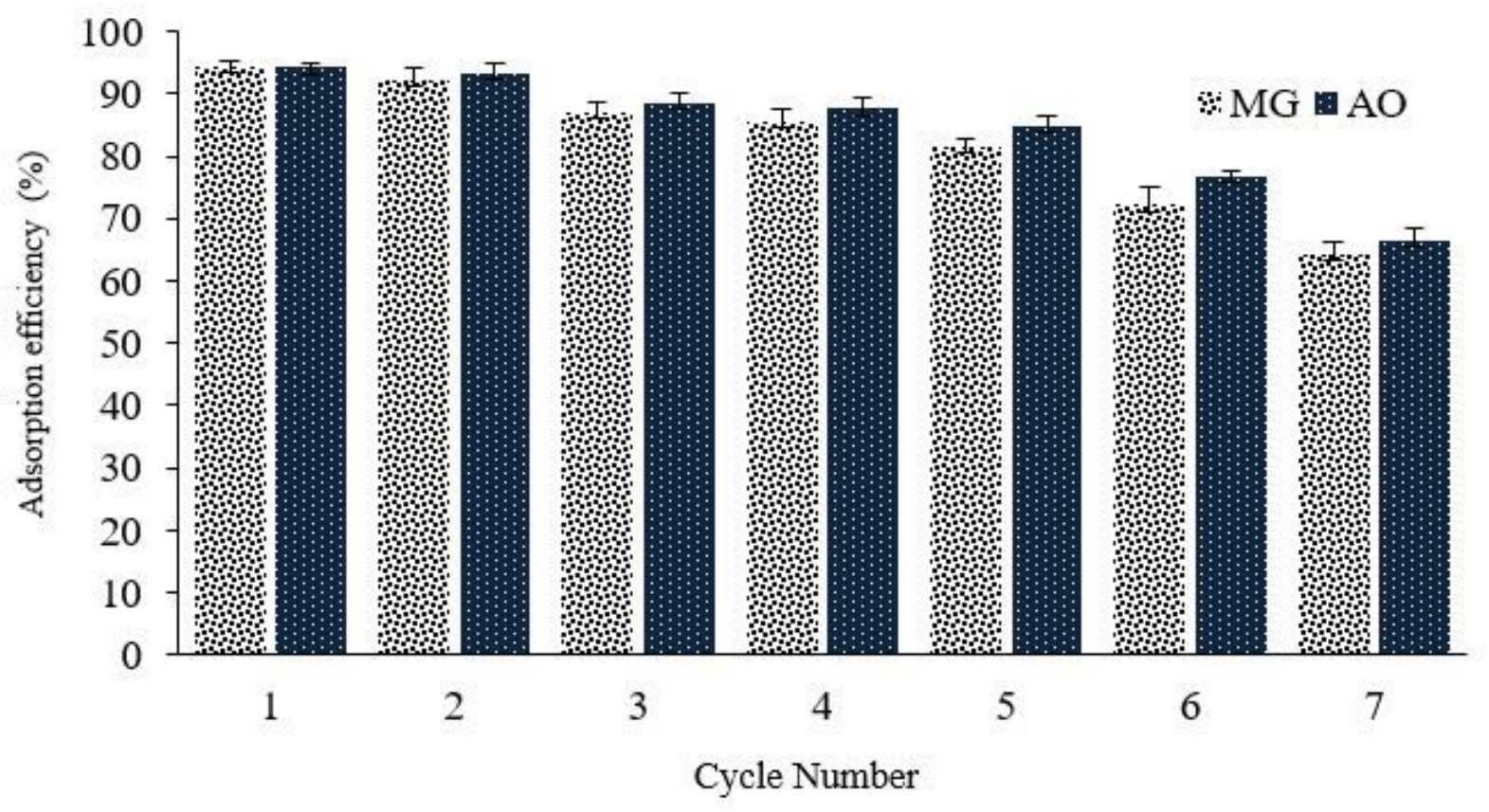

Figure 6

Effect of regeneration cycles on adsorption of dyes onto NaX nanozeolites.

\section{Supplementary Files}

This is a list of supplementary files associated with this preprint. Click to download.

- Supplementalfile.docx 